\title{
metabolites
}

ISSN 2218-1989

www.mdpi.com/journal/metabolites/

Review

\section{Application of Metabolomics in Drug Resistant Breast Cancer Research}

\author{
Ayesha N. Shajahan-Haq *, Mehar S. Cheema and Robert Clarke \\ Lombardi Comprehensive Cancer Center and Department of Oncology, Georgetown University \\ School of Medicine, 3970 Reservoir Road NW, Washington, DC 20057, USA; \\ E-Mail: bjs.cheema9@gmail.com; clarker@georgetown.edu \\ * Author to whom correspondence should be addressed; E-Mail: ans33@ georgetown.edu; \\ Tel.: +1-202-687-7451; Fax: +1-202-687-7505.
}

Academic Editor: Peter Meikle

Received: 7 February 2014 / Accepted: 24 December 2014 / Published: 16 February 2015

\begin{abstract}
The metabolic profiles of breast cancer cells are different from normal mammary epithelial cells. Breast cancer cells that gain resistance to therapeutic interventions can reprogram their endogenous metabolism in order to adapt and proliferate despite high oxidative stress and hypoxic conditions. Drug resistance in breast cancer, regardless of subgroups, is a major clinical setback. Although recent advances in genomics and proteomics research has given us a glimpse into the heterogeneity that exists even within subgroups, the ability to precisely predict a tumor's response to therapy remains elusive. Metabolomics as a quantitative, high through put technology offers promise towards devising new strategies to establish predictive, diagnostic and prognostic markers of breast cancer. Along with other "omics" technologies that include genomics, transcriptomics, and proteomics, metabolomics fits into the puzzle of a comprehensive systems biology approach to understand drug resistance in breast cancer. In this review, we highlight the challenges facing successful therapeutic treatment of breast cancer and the innovative approaches that metabolomics offers to better understand drug resistance in cancer.
\end{abstract}

Keywords: breast cancer; drug resistance; metabolomics; cellular metabolism; cell death 


\section{Introduction}

The fact that cellular metabolism of cancer cells is different from that of normal cells has been known for several decades [1]. "Warburg effect" or increased rate of aerobic glycolysis, rather than the more energy-efficient mitochondrial oxidative phosphorylation, highlights the cancer cell's needs beyond energy. With aberrantly higher rates of cell proliferation, it is not surprising that rates of aerobic glycolysis, glutaminolysis or fatty acid synthesis are also abnormally higher in cancer cells to keep up with both energy and biomass demands [2,3]. However, our understanding of the complex nature of cellular metabolic pathways in cancer remains incomplete. Changes in gene expression and protein translation can cause robust changes in the cellular metabolite profiles or metabolome. Therefore, comparing the metabolite profile of cancer cells versus normal cells can help researchers identify the metabolic changes that promote carcinogenesis. With technological advancement in mass spectrometry, high throughput metabolite profiling (metabolomics) of cancer cells or tumors allows researchers to identify and validate cellular metabolic pathways that contribute to the malignant phenotype.

Genomics studies investigate differences in sequences in nucleotides that constitute protein coding genes, non-coding DNA and regulatory regions while proteomics studies identify function of proteins in cancer cells compared with cancer cells [4]. Gene expression profiles [5-7] and proteomics [8], although expensive, in recent years have provided a glimpse into the complex genetic makeup of breast cancer subtypes and their correlation with survival, chemotherapeutic response or metastatic spread. Metabolomics is the newest layer of "omics" data that is rapidly gaining attention of breast cancer researchers worldwide. The metabolome of a cell comprises of the highly complex biochemical pathways with numerous small molecules or metabolic substrates that include amino acids, sugars, lipids and other bioactive agents. Metabolites serve as chemical byproducts or substrates of naturally occurring biochemical processes and pathways, in a biological system. Metabolomics seeks to quantify the metabolites in the metabolome, and use this data to (in relation to other "omics" fields) eventually diagnose various diseases. Hence the identification of molecular targets that underscore a drug resistant phenotype can be effectively used for developing disease modifying therapeutics. Advances in metabolomics technologies have enabled researchers to design and implement novel strategies in following cancer prognosis and development of customized therapeutics [9-11]. Complex signaling associated with cancer phenotypes occurs in the context of interactive networks [12,13] and may be further compounded by drug treatment. Thus, a systems approach using both computational and mathematical modeling may be needed to uncover how the cancer cell responds to external stress and adapts to acquire drug resistance. Precise prognostic tools in personalized medicine are needed not only to identify patients who will benefit from specific treatment options but also to determine dosing strategies to improve drug efficacy. In this review, we discuss the current challenges in drug resistance in breast cancer and what new opportunities metabolomics can provide for researchers.

\section{Breast Cancer}

\subsection{Breast Cancer Biology and Therapeutic Options}

Each year, 1.3 million new cases of breast cancer are diagnosed worldwide, and account for almost $15 \%$ of all cancer-related deaths [14]. In the United States, the number of breast cancer cases is projected 
to increase each year, and therefore, this disease, among other cancers, poses a significant burden to health care and the economy [15]. Breast cancer is a heterogeneous disease [6,16,17] with multiple subtypes and cellular/molecular characteristics, and thus, one of the major challenges for successful treatment in the clinic has been lack of reliable molecular predictors. The standard treatment option for localized breast cancer is surgery or mastectomy with or without radiation while systemic adjuvant therapies (chemotherapy, endocrine therapy or biologic therapy) are used to control tumor growth and improve survival [18]. Various clinical factors including age, menopausal status, lymph node invasion and tumor size are essential in determining the best therapeutic option for a breast cancer patient. Other essential biochemical information required for therapeutic decisions are hormone receptor status including estrogen receptor alpha (ESR1/ER), progesterone receptor (PGR/PR) or growth factor receptor status such as HER2/neu (ERBB2) expression or histological grade determined by immuno-histochemical stains (IHC) [19]. However, minor differences in review of pathology slides can greatly impact clinical decisions and patient care [20]. Moreover, hormone receptor and HER2 status may change with cancer progression and treatment [21,22] necessitating the development of precise biomarkers for breast cancer subtypes that can be monitored in real-time. Gene expression studies carried out over the last two decades studies have recently resulted in the development of gene signatures such as MammaPrint (71-genes) [23] or Oncotype DX ${ }^{\circledR}$ Recurrence Score (21-genes) [24] that can help assign a prognostic score in early breast cancer to determine benefits of adjuvant treatment.

Estrogen and estrogen receptors play significant roles in the development of human breast cancer in $70 \%$ of breast cancer cases that are ER-positive [25]. Pharmacological agents and that inhibit estrogen signaling are collectively referred to as endocrine therapy and is commonly used as initial treatment option for breast cancer that is ER /PR-positive. The purpose of such therapy is to block ER activity with antiestrogens such as Tamoxifen or Faslodex/Fulvustrant/ICI [26-29] or to diminish estrogen-mediated signaling by reducing estrogen synthesis with aromatase inhibitors [30-32]. In menopausal women, aromatase inhibitor such as Letrozole/Femara is superior to Tamoxifen as a first-line treatment [33]. HER2-positive breast cancer constitutes about $20 \%$ of all types of breast cancer and is characterized by aggressive disease progression and poor prognosis. Targeted therapies for HER2-positive tumors include trastuzumab or pertuzumab, anti-HER2 monoclonal antibodies [34,35], lapatinib, a small-molecule tyrosine kinase inhibitor directed both to HER2 and HER1 [36] or trastuzumab emtansine (T-DM1), an antibodydrug conjugate [37]. Triple-negative breast cancer (TNBC; ER-/PR-/HER2-) accounts for about 15-17\% of all types of breast cancer cases but this group has a heterogeneous molecular profile. Antiestrogens and anti-HER2 therapeutics are ineffective in treating TNBC, which remains a subgroup of breast cancer without any specific target. Some TNBCs can be cured by surgery followed by standard chemotherapy (anthracycline/taxane or taxane with carboplatin). Other therapeutic drugs currently in clinical trials for TNBC include agents that are anti-angiogenic, anti-EGFR, poly(ADP-ribose) polymerases (PARP) inhibitors, anti-Src kinase, PI3K and CDKs [38].

\subsection{Drug Resistance in Breast Cancer}

Regardless of biochemical subtypes or clinical subgroups, drug resistance in all types of breast cancer remains an unsolved clinical problem. While a vast majority of breast cancers are treated with endocrine therapy, about $40 \%-50 \%$ of these tumors will display de novo or acquired resistance $[39,40]$. Although 
various studies using genomics technologies have shed light on the ER-regulated pathways that may contribute to the antiestrogen resistant phenotype [41-43], identification of precise biomarkers of antiestrogen responsiveness remains elusive. Proteomic studies have recently uncovered ER-associated co-regulators and transcription factors as possible targets in endocrine resistant breast cancers [8,44]. In HER2-positive breast cancer, treatment with trastuzumab along with standard chemotherapy has significantly improved survival in the past decade [45]; however, resistance remains a critical setback. Increased activity of other HER family members and crosstalk with signaling pathways such as $\mathrm{PI} 3 \mathrm{~K} / \mathrm{AKT}$ are among various other factors contributing to trastuzumab resistance in HER2-positive breast cancer [38]. Chemoresistant TNBC tend to have an aggressive clinical course with early relapse [46]. Master regulators of cellular metabolomics such as MYC, p53 and MTOR are mutated in various subgroups of breast cancer [47,48]. Since MYC, p53 and MTOR are known to impact metabolic pathway, therefore, critical evaluation of cellular metabolic pathways, along with protein function, should be investigated to better understand the pathobiology of breast cancer and drug responsiveness.

While the molecular basis of drug resistance in breast cancer remains unknown, concomitant deregulation of cell death pathways to promote cell survival in response to anti-cancer therapy is evident $[13,40,49-51]$. Research from our group has shown the important role of apoptosis, autophagy and necrosis in cell death in ER+ breast cancer induced by antiestrogen or chemotherapeutic agents [52-59]. Programmed cell death (PCD) pathway such as apoptosis (PCD1), autophagy (PCD2), or necrosis (PCD3) are closely regulated in neoplasia and major molecular inhibitors of these pathways are often overexpressed in tumors. For example, BCL2 [54], NFkB (RELA) [56,57], XBP1 [55], HSP5A/GRP78 [53] MYC [60,61] are known to be overexpressed in breast cancer cells or tumors that are resistant to antiestrogens. In the cell, these molecules not only inhibit cell death, they regulate numerous other processes including cellular metabolism [50]. Moreover, overexpression of these pro-survival molecules allows cancer cells to achieve rapid recovery from disruptions in glucose/ATP levels or amino acid synthesis induced by therapeutic agents. In the normal breast, extensive production of milk proteins is carefully regulated to avoid the endoplasmic reticulum (ER) stress due to an excess load of these proteins and induction of the unfolded protein response (UPR). The UPR protects the cells under normal conditions and helps restore homeostasis. In breast cancer cells, UPR can be triggered by a variety of sources including nutrient deprivation, hypoxia and therapeutic interventions. Both cytotoxic and endocrine therapeutics can induce UPR in different cancer cells $[53,62]$. Oncoproteins such as MYC that are master regulators of cellular metabolic pathways can also regulate the UPR [63,64]. MYC is increased in antiestrogen resistant cells and tumors $[60,61,64]$. MYC can increase the dependency of breast cancer cells on glutamine and glucose for cell survival [64]. However, the presence of glutamine in glucose deprived conditions can initiated an UPR-mediated re-programming of metabolic pathways allows cellular adaptation and increased dependency on glutamine that is regulated by MYC and the UPR. The endpoint of UPR induction in cancer cells can be either prodeath or prosurvival and depends on the nature and duration of the stress. Therefore, a complex regulatory mechanism exists to control the UPR in carcinogenesis with key factors from both cell death and survival pathways [50]. 


\section{Metabolomics as a Promising New Tool in Breast Cancer Research}

\subsection{Current Metabolomics Technologies}

Metabolomics is a rapidly emerging field of research that aims to detect and quantify alterations in small-molecule abundance that is known collectively as the metabolome [22,65]. Akin to gene and protein expression that differs across the various cell types of the body, the metabolome is also contextdependent, and varies in organs, tissues and cells, and, importantly, in health and disease processes and external stimuli [66,67]. Metabolomics is the downstream complement of "omics" technologies that span genomics, transcriptomics, RNAseq and proteomics, and thus provides the basis for development of a comprehensive systems biology understanding of stress signaling in injury and disease, which is relevant to many fields such as pharmacology, diabetes, and cancer [68,69]. Traditionally, Nuclear Magnetic Resonance (NMR) was used for metabolomics profiling and early reports of biomarker discovery in breast cancer used this technology [70,71]. However, NMR lacked the sensitivity for detection of low abundance metabolites that could be used as specific and sensitive biomarkers for early detection and staging breast cancer cases. Moreover, in the recent years, there have been dramatic technological advancements in mass spectrometry leading to higher sensitivity and resolution for metabolomic profiling. Many of the problems intrinsic to the NMR-based metabolomics studies thus can be circumvented through the use of liquid chromatography (LC) or gas chromatography in conjunction with high resolution mass spectrometry (MS) [72]. One of the main advantages of mass spectrometry is that constituents of the biological matrix are usually resolved as discreet peaks in a chromatogram that yields an accurate mass and can be subjected to tandem MS that can yield unequivocal identities of large numbers of analytes. These ions representing a unique metabolite are readily amenable to quantification. When combined with ultra-performance liquid chromatography (UPLC), high resolution MS instrumentation can typically yield more than 4000 features that need to be characterized for identification of predictive metabolite markers. The ability to analyze the samples in positive and negative electrospray ionization mode yields complimentary information thus widening the metabolome coverage. Each of these features possesses a characteristic retention time value on the LC column, a mass-to-charge ratio, and an intensity value $[73,74]$. A typical metabolomic experiment performed using these methodologies can easily generate a large number of data points with high dimensionality. Comprehensive informatics approaches including multivariate data analysis (MDA) methods are then used for data reduction, noise filtration and biomarker selection. One of the main advantages of using GC-MS is the ability to use spectral libraries for unambiguous metabolite identification [75]. However, since the metabolome is highly sensitive to perturbations several aspects have to be carefully considered to minimize variability and low signal to noise that is commonly associated with clinical cohort studies. An important aspect of the study design is to control for preanalytic variables such as sample collection, storage and the number of freeze thaw cycles that influence the downstream results.

\subsection{Metabolites as Powerful Biomarkers of Breast Cancer}

Given the high prevalence and mortality associated with breast cancer, there is an urgent need for biomarkers that can be used in the clinic for identifying at risk individuals, for monitoring disease progression as well as for assessing the response to therapy [76,77]. An ideal biomarker should be specific, sensitive 
be assayable in a cost-effective, high through put manner. Metabolomics has several advantages as a quantitative, high through put technology that can be used to develop predictive, diagnostic and prognostic markers of breast cancer. Early observation by Warburg established that cancer cells switch to a glycolytic phenotype thus reprograming metabolism that promotes cell division and proliferation $[1,78]$. Subsequently, several studies have shown the role of glycolytic flux in oncogenesis of breast cancer [79-82]. Given the metabolic reprograming in cancer, it is reasonable to assume that some of these alterations would be stable and amenable to quantitative measurements for diagnostic and prognostic purposes. Several studies have thus used a metabolomic approach to discern alterations in breast cancer that could be potentially used for disease stratification [4,83-87]. Budczies et al. found alterations in beta-alanine and glutamine metabolism in estrogen receptor positive (ER+) as compared to ER- breast cancer [88]. Using an NMR approach, Jobard et al. reported a panel of metabolites including histidine, acetoacetate, glycerol, pyruvate, glycoproteins ( $\mathrm{N}$-acetyl), mannose, glutamate and phenylalanine that could discriminate patients with metastatic breast cancer from those with localized disease with a specificity of 79.8\% [89]. Metabolomics has also been used for unraveling diagnostic biomarkers of non-invasive breast cancer which has been comprehensively reviewed [10]. Qiu et al. used a quantitative mass spectrometry based plasma metabolomics to identify a lipid panel that could distinguish breast cancer patients from healthy controls [90]. Metabolomics had also been used to study response to neo-adjuvant chemotherapy, tumor microenvironment and response to hypoxia breast cancer [91-94]. Metabolomics has also helped further the understanding of how central carbon metabolism is altered in tumor tissues as compared to normal [95]. Martinez-Outschoorn et al. have reported an association of elevated ketones and lactate with increased "stemness" of breast cancer cells while other metabolomic studies have reported increased oxidative stress in these cells [96]. The term "oncometabolite" is used to describe cellular metabolites that abnormally accumulate in cancer cells and tumors and are associated with malignant phenotype [9,97]. Oncometabolites such as fumarate, succinate, and D-2-hydroxyglutarate can drive oncogenesis partly by regulating epigenetic changes in certain types of cancer [98]. Through metabolomic analysis, Jain et al have identified glycine as an important metabolite that promotes rapid cell proliferation in breast cancer cells [99]. Although a lot of studies in the recent years have successfully utilized a metabolomics approach, future validation studies with independent cohorts would be critical for determining the efficacy and clinical utility of these biomarkers.

\subsection{Uncovering New Therapeutic Targets through Metabolomics}

It is well known that although two individuals may be clinically diagnosed with breast cancer, their tumors' response to therapy may vary depending on the intrinsic molecular heterogeneity of the tumor [100-102]. Thus, understanding the specific biochemical changes accompanying the disease sub type offers an attractive platform for the development of novel therapeutics that can be used to customize response thus improving clinical outcomes in breast cancer $[103,104]$. The ability to simultaneously measure thousands of metabolites, allows for identification of key metabolic pathways that are under or over represented in breast carcinogenesis. To date, several studies in breast cancer cell models, tumors, serum or urine have been used to understand the underlying causes of breast cancer progression and response to specific anti-cancer therapy (Table 1). These studies support the idea that metabolomics can be a useful tool to differentiate breast cancer subtypes, and also provide a glimpse 
into the cellular processes in response to anti-cancer therapy. Comparing the changes in metabolites in cancer cells and tumors that are sensitive or resistant to commonly used breast cancer therapies, for example, antiestrogens or taxol, can help investigators determine the biochemical processes that are correlated with cell death or survival.

Collectively, these studies highlight the importance of metabolomics as a powerful tool to understand the biochemical differences between normal and tumors tissue, and between the various sub-typed of breast cancer. Development of accurate detection tools with metabolites that can serve as biomarkers for disease state or drug responsiveness from serum or urine may provide non-invasive diagnostic approaches in the clinic. These studies also underscore the gaps in the field of breast carcinogenesis and drug responsiveness. While the recent surge in metabolomics-driven research in cancer is commendable, thorough studies involving the contributions of the tumor microenvironment should be included in analysis and validation. Thus, more in vivo metabolomics studies for breast cancer subtypes and treatment groups are needed to determine the role of the biochemical pathways that may provide essential insights into the tumor microenvironment and the mechanism of drug resistance leading to recognition of molecular targets that can be used for the development of targeted therapeutics [105].

Table 1. Studies involving metabolomics analysis aimed at understanding breast cancer progression and identifying new molecular targets.

\begin{tabular}{|c|c|c|c|c|}
\hline Biological materials & Approach & Specific treatment & Metabolic pathways identified & Reference \\
\hline $\begin{array}{l}\text { ER+ and ER- tumor } \\
\text { tissues }\end{array}$ & GC-MS & None & $\begin{array}{l}\text { Increase in glutamate, xanthine, beta- } \\
\text { alanine in the ER- disease }\end{array}$ & {$[88]$} \\
\hline MCF7 (ER+) & GC-MS & adriamycin & $\begin{array}{l}\text { Increase in glycerol metabolism and } \\
\text { decrease in glutathione biosynthesis }\end{array}$ & [106] \\
\hline MDA-MB-231 (ER-) & NMR & hypoxia & $\begin{array}{l}\text { Increase in glutamate, valine, and } \\
\text { leucine and decrease in proline, } \\
\text { creatine, alanine }\end{array}$ & [107] \\
\hline MCF7 (ER+) & NMR & ascididemin & $\begin{array}{l}\text { Increase in citrate, gluconate and } \\
\text { polyunsaturated fatty acids and } \\
\text { decrease in glycerophospho-choline } \\
\text { and -ethanolamine }\end{array}$ & [108] \\
\hline $\begin{array}{l}\text { serum: early and } \\
\text { metastatic breast } \\
\text { cancer }\end{array}$ & NMR & None & $\begin{array}{l}\text { Increase in histidine, acetoacetate, } \\
\text { glycerol, pyruvate, glycoproteins (N- } \\
\text { acetyl), mannose, glutamate and } \\
\text { phenylalanine and decrease in alanine }\end{array}$ & [89] \\
\hline $\begin{array}{l}\text { MCF7 (ER+) and } \\
\text { MDA-MB-231 (ER-) }\end{array}$ & NMR & $\begin{array}{l}\text { curcumin }+/ \text { - docetaxel } \\
\text { (dose- and time- } \\
\text { response })\end{array}$ & $\begin{array}{l}\text { Changes in glutathione metabolism, } \\
\text { lipid metabolism, and glucose } \\
\text { utilization - some biphasic changes } \\
\text { depending on exposure }\end{array}$ & [109] \\
\hline $\begin{array}{l}\text { MCF7 (ER+) and } \\
\text { MDA-MB-231 (ER-) }\end{array}$ & LC-MS & resveratrol & $\begin{array}{l}\text { Increased amino acid and arachidonic } \\
\text { acid in both cell lines }\end{array}$ & [110] \\
\hline
\end{tabular}


Table 1. Cont.

\begin{tabular}{|c|c|c|c|c|}
\hline Biological materials & Approach & Specific treatment & Metabolic pathways identified & Reference \\
\hline $\begin{array}{l}\text { serum: recurrent and } \\
\text { non-recurrent breast } \\
\text { cancer }\end{array}$ & $\begin{array}{l}\text { NMR \& } \\
\text { GC-MS }\end{array}$ & None & $\begin{array}{l}\text { Changes in amino acids metabolism } \\
\text { (glutamic acid, histidine, proline and } \\
\text { tyrosine), glycolysis (lactate), } \\
\text { phospholipid metabolism (choline) } \\
\text { and fatty acid metabolism } \\
\text { (nonanedioic acid) }\end{array}$ & [83] \\
\hline $\begin{array}{l}\text { urine: early-/late-stage } \\
\text { breast cancer and } \\
\text { normal }\end{array}$ & NMR & None & $\begin{array}{l}\text { Changes in metabolites relating to } \\
\text { energy metabolism, amino acids, and } \\
\text { gut microbial metabolism }\end{array}$ & [111] \\
\hline
\end{tabular}

\section{Current Challenges in Metabolomics-Based Breast Cancer Research}

\subsection{Metabolomics Complements Other "Omics” Disciplines in a Systems Biology Approach towards Precision Medicine}

A systems biology approach to treatment and research facilitates in lending a holistic view of the intricate relations of various biological systems, in terms of the population or patient in question. Systems biology is a developing research paradigm and has been seen, in some cases, as more effective than the previously more habitual, reductionism [112,113]. It embraces the idea of an all-inclusive perspective that takes into account all biological pathways at work, in coherence with each other and has been reviewed in details $[114,115]$. It relies on the premise that the pathophysiology of cancer progression results from a malfunction of molecular networks and hence [8-10,116-118] a comprehensive understanding of pathway based response at different levels of cellular expression, would yield new insights into tumor heterogeneity thus augmenting the personalized medicine paradigm [11,119]. Alterations in specific metabolic pathways can be used not only for understanding the molecular mechanism of disease progression but also for identification of molecular targets that can be used for therapeutic development. Qualitative and quantitative assessment of metabolite levels in urine, blood, needle biopsies or ductal lavage fluids offers promise in identification of predictive biomarkers of breast cancer that can be used for early detection, diagnosis and disease stratification. The challenge of Systems biology lies in effective data integration of metabolomics data with other "omics" data as well as clinical correlates to understand disease progression [120,121]. Initial biomarker discovery studies need to be followed up by large scale validation studies with diverse cohorts, nevertheless metabolomics holds promise for improvising strategies for individualized approach and personalized therapy [122].

Metabolomics-based research can be divided into two different categories: non-targeted and targeted metabolomics. Non-targeted metabolomics tries to uncover and identify new chemical compounds that could prove quintessential in understanding the change in a biological systems state of health. These new metabolites, for example could be produced because of a change in the state of the being's existence, environmental factors, etc., and these changes could lead to a diagnoses of the beings condition [123,124]. For example, non-targeted metabolomics of breast tumors from a patient could be a composite of several factors, including age, gender, hormone status, drug treatment and pharmacogenetics (Figure 1). 


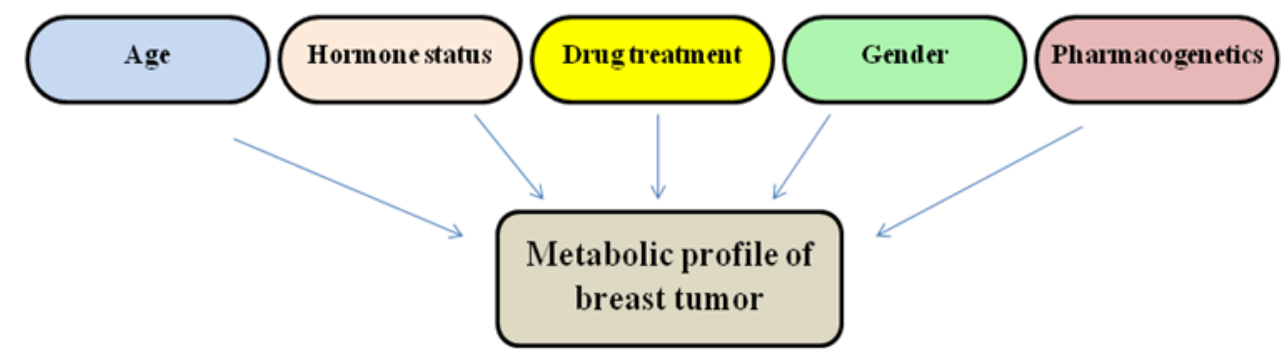

Figure 1. Metabolomics analysis of tumors depends on multiple factors associated with an individual patient.

\subsection{Targeting Metabolic Pathways in Cancer}

Altered metabolic pathways are rational, potential therapeutic targets. Although the mechanistic details remain unclear, it is becoming increasingly evident that oncoproteins regulate cellular metabolism, such as glycolysis [125] and glutaminolysis [126], to provide energy and substrates to the highly proliferative cancer cell. In addition, increased glycolysis has been linked to drug resistance in cervical cancer cells through pyruvate dehydrogenase kinase (PDK) isoforms PDK1 and PDK3 [127] and through increased lactate production in colon cancer cells [128]. Inhibiting PDK with dichloroacetate (DCA), shifts metabolism from glycolysis to glucose oxidation, inhibits tumor growth and induces apoptosis in several types of cancer [129]. Intermediates generated via glycolysis promote the pentose phosphate pathway (PPP) to generate NADPH and ribose-5-phosphate that are essential for lipid and nucleic acid synthesis, respectively [130]. NADPH is needed to maintain adequate cellular levels of the antioxidant glutathione (GSH), a tripeptide of glutamate, cysteine and glycine that is dependent on glutaminolysis [131]. High levels of GSH have been implicated in chemoresistance in cancer [132].

Studies focused on specific enzymes and intermediate metabolites involved in cellular metabolic pathways highlight the importance of these biochemical processes on cell survival and resistance to anticancer therapy. Transketolase (TKT) or transketolase-like protein 1 (TKTL1), enzymes in the PPP, sustains viability of tumor cells [133] and confers resistance to anti-EGFR antibody therapy [134] and imatinib [135]. Hexokinase II (HK2), localized to the outer membrane of mitochondria, is highly expressed in various cancers and can inhibit apoptosis [136] and promote cell proliferation [137]. Glyceraldehyde-3-phosphate dehydrogenase (GAPDH) is overexpressed in cancer [138] and may promote resistance to chemotherapy by inducing Bcl-xL overexpression [139]. Expression of an embryonic M2 isoform of pyruvate kinase (PKM2) promotes tumorigenesis [140] and is regulated by hypoxia-inducible factor-1 (HIF-1) in reprogramming of glucose metabolism in cancer [141]. Specific isoforms of lactate dehydrogenase (LDH) and monocarboxylate transporters (MCTs) are differentially expressed in ER+ and ER- breast cancer cells depending on the cellular demand for glycolysis [142]. Also, the MTOR pathway in cancer cells can detect environmental conditions and adjust cellular metabolic processes by sensing intercellular energy levels through AMPK [143]. Enzymes involved in serine metabolism has helped identify a potential role of serine metabolism in aggressive TNBC [144]. Connecting the expression levels of enzymes widely available gene expression data with metabolites of pathways in different breast cancer subtypes and treatment conditions, therefore, allows investigators to identify critical metabolic pathways that drive a specific phenotype. Thus, knowledge of the metabolic 
pathways that sustain cancer cell survival within tumors can be used to design better anti-cancer therapeutics to avert drug resistance.

\section{Conclusions}

Breast cancer is a heterogeneous disease and the recent progress in uncovering the molecular makeup of the disease has guided researchers and clinicians to reject a one-size-fits-all approach to treatment. Successful use of metabolomics in identifying breast cancer biomarkers for specific subtypes or drug responsiveness will provide non-invasive methods to accurately define characteristics of a patient's cancer in the clinic from body fluids such as blood, urine, sweat or nipple aspirates. Moreover, identification oncometabolites will help target the metabolic pathways that promote cell survival and drug resistance. Efficient management and analysis tools for large volume of data from breast cancer cell models or patient samples and better mode of integration of metabolomics data with transcriptomics and proteomics data to translate the high-throughput information to clinical diagnosis can help accelerate the translation of new findings in the laboratory to the clinic.

\section{Acknowledgments}

This work was supported in part by Public Health Service awards R01-CA131465 and U54-CA149147 to RC.

\section{Conflict of Interest}

The authors declare no conflict of interest.

\section{References}

1 Warburg, O.; Wind, F.; Negelein, E. The metabolism of tumors in the body. J. Gen. Physiol. 1927, $8,519-530$.

2 Munoz-Pinedo, C.; Mjiyad, El. N.; Ricci. J.E. Cancer metabolism: Current perspectives and future directions. Cell Death Dis. 2012, 3, e248.

3 Vander Heiden, M.G. Exploiting tumor metabolism: Challenges for clinical translation. J. Clin. Invest. 2013, 123, 3648-3651.

4 Tyers, M.; Mann, M. From genomics to proteomics. Nature 2003, 422, 193-197.

5 Cadoo, K.A.; Fornier, M.N.; Morris, P.G. Biological subtypes of breast cancer: Current concepts and implications for recurrence patterns. Q. J. Nucl. Med. Mol. Imaging 2013, 57, 312-321.

6 Curtis, C.; Shah, S.P.; Chin, S.F.; Turashvili, G.; Rueda, O.M.; Dunning, M.J. Speed, D.; Lynch, A.G.; Samarajiwa, S.; Yuan, Y. et al. The genomic and transcriptomic architecture of 2000 breast tumours reveals novel subgroups. Nature 2012, 486, 346-352.

7 Peintinger, F. Using molecular profiles to tailor treatment in breast cancer: Are they ready for prime time? Curr. Opin. Obstet. Gynecol. 2014, 26, 21-26.

8 Mohammed, H.; Carroll, J.S. Approaches for assessing and discovering protein interactions in cancer. Mol. Cancer Res. 2013, 11, 1295-1302. 
9 Yang, M.; Soga, T.; Pollard, P.J. Oncometabolites: Linking altered metabolism with cancer. J. Clin. Invest. 2013, 123, 3652-3658.

10 Zhang, A.H. Metabolomics in noninvasive breast cancer. Clin. Chim. Acta 2013, 424, 3-7.

11 Zhao, Y.; Butler, E.B.; Tan, M. Targeting cellular metabolism to improve cancer therapeutics. Cell Death Dis. 2013, 4, e532.

12 Clarke, R.; Ressom, H.W.; Wang, A.; Xuan, J.; Liu, M.C.; Gehan, E.A.; Wang, Y. The properties of high-dimensional data spaces: Implications for exploring gene and protein expression data. Nat. Rev. Cancer 2008, 8, 37-49.

13 Clarke, R.; Shajahan, A.N.; Riggins, R.B.; Cho, Y.; Crawford, A.; Xuan, J.; Wang, Y.; Zwart, A.; Nehra, R.; Liu, M.C. Gene network signaling in hormone responsiveness modifies apoptosis and autophagy in breast cancer cells. J. Steroid Biochem. Mol. Biol. 2009, 114, 8-20.

14 Jemal, A.; Bray, F.; Center, M.M.; Ferlay, J.; Ward, E.; Forman, D. Global cancer statistics. $C A$ Cancer J. Clin. 2011, 61, 69-90.

15 Montero, A.J.; Eapen, S.; Gorin, B.; Adler, P. The economic burden of metastatic breast cancer: A U.S. managed care perspective. Breast Cancer Res. Treat 2012, 134, 815-822.

16 Schnipper, L. Clinical implications of tumor-cell heterogeneity. N. Engl. J. Med. 1986, 314, 1423-1431.

17 Shah, S.P.; Roth, A.; Goya, R.; Oloumi, A.; Ha, G.; Zhao, Y.; Turashvili, G.; Ding, J.; Tse, K.; Haffari, G. et al. The clonal and mutational evolution spectrum of primary triple-negative breast cancers. Nature 2012, 486, 395-399.

18 Matsen, C.B.; Neumayer, L.A. Breast cancer: A review for the general surgeon. JAMA Surg. 2013, 148, 971-979.

19 Hammond, M.E.; Hayes, D.F.; Dowsett, M.; Allred, D.C.; Hagerty, K.L.; Badve, S.; Fitzgibbons, P.L.; Francis, G.; Goldstein, N.S.; Hayes, M. et al. American Society of Clinical Oncology/College of American Pathologists guideline recommendations for immunohistochemical testing of estrogen and progesterone receptors in breast cancer. J. Clin. Oncol. 2010, 28, 2784-2795.

20 Jorns, J.M.; Healy, P.; Zhao, L. Review of estrogen receptor, progesterone receptor, and HER2/neu immunohistochemistry impacts on treatment for a small subset of breast cancer patients transferring care to another institution. Arch. Pathol. Lab. Med. 2013, 137, 1660-1663.

21 Allegra, J.C.; Barlock, A.; Huff, K.K.; Lippman, M.E. Changes in multiple or sequential estrogen receptor determinations in breast cancer. Cancer 1980, 45, 792-794.

22 Liesenfeld, D.B.; Habermann, N.; Owen, R.W.; Scalbert, A.; Ulrich, C.M. Review of mass spectrometry-based metabolomics in cancer research. Cancer Epidemiol. Biomarkers Prev. 2013, 22, 2182-2201.

23 Van't Veer, L.J.; Dai, H.; van de Vijver, M.J.; He, Y.D.; Hart, A.A.; Mao, M.; Peterse, H.L.; van der Kooy, K.; Marton, M.J.; Witteveen, A.T. et al. Gene expression profiling predicts clinical outcome of breast cancer. Nature 2002, 415, 530-536.

24 Paik, S.; Shak, S.; Tang, G.; Kim, C.; Baker, J.; Cronin, M.; Baehner, F.L.; Walker, M.G.; Watson, D.; Park, T.; et al. A multigene assay to predict recurrence of tamoxifen-treated, node-negative breast cancer. N. Engl. J. Med. 2004, 351, 2817-2826. 
25 Anderson, W.F.; Chatterjee, N.; Ershler, W.B.; Brawley, O.W. Estrogen receptor breast cancer phenotypes in the Surveillance, Epidemiology, and End Results database. Breast Cancer Res. Treat. 2002, 76, 27-36.

26 Clarke, R.; Skaar, T.; Baumann, K.; Leonessa, F.; James, M.; Lippman, J.; Thompson, E.W.; Freter, C.; Brunner, N. Hormonal carcinogenesis in breast cancer: Cellular and molecular studies of malignant progression. Breast Cancer Res. Treat. 1994, 31, 237-248.

27 Fisher, B.; Costantino, J.; Redmond, C.; Poisson, R.; Bowman, D.; Couture, J.; Dimitrov, N.V.; Wolmark, N.; Wickerham, D.L.; Fisher, E.R. A randomized clinical trial evaluating tamoxifen in the treatment of patients with node-negative breast cancer who have estrogen-receptor-positive tumors. N. Engl. J. Med. 1989, 320, 479-484.

28 Howell, A. Selective oestrogen receptor downregulator. Eur. J. Cancer 2002, 38 (Suppl. 6), S61-S62.

29 Howell, A.; Robertson, J.F.; Quaresma, A.J.; Aschermannova, A.; Mauriac, L.; Kleeberg, U.R.; Vergote, I.; Erikstein, B.; Webster, A.; Morris, C. Fulvestrant, formerly ICI 182,780, is as effective as anastrozole in postmenopausal women with advanced breast cancer progressing after prior endocrine treatment. J. Clin. Oncol. 2002, 20, 3396-3403.

30 Buzdar, A.; Jonat, W.; Howell, A.; Jones, S.E.; Blomqvist, C.; Vogel, C.L.; Eiermann, W.; Wolter, J.M.; Azab, M.; Webster, A.; et al. Anastrozole, a potent and selective aromatase inhibitor, versus megestrol acetate in postmenopausal women with advanced breast cancer: results of overview analysis of two phase III trials. Arimidex Study Group. J. Clin. Oncol. 1996, 14, 2000-2011.

31 Gershanovich, M.; Chaudri, H.A.; Campos, D.; Lurie, H.; Bonaventura, A.; Jeffrey, M.; Buzzi, F.; Bodrogi, I.; Ludwig, H.; Reichardt, P. et al. Letrozole, a new oral aromatase inhibitor: randomised trial comparing $2.5 \mathrm{mg}$ daily, $0.5 \mathrm{mg}$ daily and aminoglutethimide in postmenopausal women with advanced breast cancer. Letrozole International Trial Group (AR/BC3). Ann. Oncol. 1998, 9 , 639-645.

32 Howell, A.; Buzdar, A. Are aromatase inhibitors superior to antiestrogens? J. Steroid Biochem. Mol. Biol. 2005, 93, 237-247.

33 Mouridsen, H.; Gershanovich, M.; Sun, Y.; Perez-Carrion, R.; Boni, C.; Monnier, A.; Apffelstaedt, J.; Smith, R.; Sleeboom, H.P.; Janicke, F.; et al. Superior efficacy of letrozole versus tamoxifen as first-line therapy for postmenopausal women with advanced breast cancer: results of a phase III study of the International Letrozole Breast Cancer Group. J. Clin. Oncol. 2001, 19, 2596-2606.

34 Baselga, J.; Cortes, J.; Kim, S.B.; Im, S.A.; Hegg, R.; Im, Y.H.; Roman, L.; Pedrini, J.L.; Pienkowski, T.; Knott, A. Pertuzumab plus trastuzumab plus docetaxel for metastatic breast cancer. N. Engl. J. Med. 2012, 366, 109-119.

35 Slamon, D.J.; Leyland-Jones, B.; Shak, S.; Fuchs, H.; Paton, V.; Bajamonde, A.; Fleming, T.; Eiermann, W.; Wolter, J.; Pegram, M.; et al. Use of chemotherapy plus a monoclonal antibody against HER2 for metastatic breast cancer that overexpresses HER2. N. Engl. J. Med. 2001, 344, 783-792.

36 Geyer, C.E.; Forster, J.; Lindquist, D.; Chan, S.; Romieu, C.G.; Pienkowski, T.; Jagiello-Gruszfeld, A.; Crown, J.; Chan, A.; Kaufman, B.; et al. Lapatinib plus capecitabine for HER2-positive advanced breast cancer. N. Engl. J. Med. 2006, 355, 2733-2743. 
37 Verma, S.; Miles, D.; Gianni, L.; Krop, I.E.; Welslau, M.; Baselga, J.; Pegram, M.; Oh, D.Y.; Dieras, V.; Guardino, E.; et al. Trastuzumab emtansine for HER2-positive advanced breast cancer. N. Engl. J. Med. 2012, 367, 1783-1791.

38 Mohamed, A.; Krajewski, K.; Cakar, B.; Ma, C.X. Targeted therapy for breast cancer. Am. J. Pathol. 2013, 183, 1096-1112.

39 Clarke, R.; Skaar, T.C.; Bouker, K.B.; Davis, N.; Lee, Y.R; Welch, J.N.; Leonessa, F. Molecular and pharmacological aspects of antiestrogen resistance. J. Steroid Biochem. Mol. Biol. 2001, 76, 71-84.

40 Clarke, R.; Liu, M.C.; Bouker, K.B.; Gu, Z.; Lee, R.Y.; Zhu, Y.; Skaar, T.C.; Gomez, B.; O’Brien, K.; Wang, Y.; et al. Antiestrogen resistance in breast cancer and the role of estrogen receptor signaling. Oncogene 2003, 22, 7316-7339.

41 Frasor, J.; Danes, J.M.; Komm, B.; Chang, K.C.; Lyttle, C.R.; Katzenellenbogen, B.S. Profiling of estrogen up- and down-regulated gene expression in human breast cancer cells: insights into gene networks and pathways underlying estrogenic control of proliferation and cell phenotype. Endocrinology 2003, 144, 4562-4574.

42 Kong, S.L.; Li, G.; Loh, S.L.; Sung, W.K.; Liu, E.T. Cellular reprogramming by the conjoint action of ERalpha, FOXA1, and GATA3 to a ligand-inducible growth state. Mol. Syst. Biol. 2011, 7, 526.

43 Loi, S.; Piccart, M.; Sotiriou, C. The use of gene-expression profiling to better understand the clinical heterogeneity of estrogen receptor positive breast cancers and tamoxifen response. Crit. Rev. Oncol. Hematol. 2007, 61, 187-194.

44 Mohammed, H.; D’Santos, C.; Serandour, A.A.; Ali, H.R.; Brown, G.D.; Atkins, A.; Rueda, O.M.; Holmes, K.A.; Theodorou, V.; Robinson JL, et al. Endogenous purification reveals GREB1 as a key estrogen receptor regulatory factor. Cell Rep. 2013, 3, 342-349.

45 Romond, E.H.; Perez, E.A.; Bryant, J.; Suman, V.J.; Geyer, C.E., Jr.; Davidson, N.E.; Tan-Chiu, E.; Martino, S.; Paik, S.; Kaufman, P.A.; et al. Trastuzumab plus adjuvant chemotherapy for operable HER2-positive breast cancer. N. Engl. J. Med. 2005, 353, 1673-1684.

46 Criscitiello, C.; Azim, H.A., Jr.; Schouten, P.C.; Linn, S.C.; Sotiriou, C. Understanding the biology of triple-negative breast cancer. Ann. Oncol. 2012, 23 (Suppl. 6). VI13-VI18.

47 Ward, P.S.; Thompson, C.B. Signaling in control of cell growth and metabolism. Cold Spring Harb. Perspect. Biol. 2012, 4, a006783.

48 Ward, P.S.; Thompson, C.B.; Metabolic reprogramming: A cancer hallmark even warburg did not anticipate. Cancer Cell 2012, 21, 297-308.

49 Clarke, R.; Shajahan, A.N.; Wang, Y,; Tyson, J.J.; Riggins, R.B.; Weiner, L.M.; Bauman, W.T.; Xuan, J.; Zhang, B.; Facey, C.; et al. Endoplasmic reticulum stress, the unfolded protein response, and gene network modeling in antiestrogen resistant breast cancer. Horm. Mol. Biol. Clin. Investig. 2011, 5, 35-44.

50 Clarke, R.; Cook, K.L.; Hu, R.; Facey, C.O.; Tavassoly, I.; Schwartz, J.L.; Baumann, W.T.; Tyson, J.J.; Xuan, J.; Wang, Y.; et al. Endoplasmic reticulum stress, the unfolded protein response, autophagy, and the integrated regulation of breast cancer cell fate. Cancer Res. 2012, 72, 1321-1331.

51 Riggins, R.B.; Bouton, A.H.; Liu, M.C.; Clarke, R. Antiestrogens, aromatase inhibitors, and apoptosis in breast cancer. Vitam. Horm. 2005, 71, 201-237. 
52 Bouker, K.B.; Skaar, T.C.; Fernandez, D.R.; O’Brien, K.A.; Riggins, R.B.; Cao, D.; Clarke, R. interferon regulatory factor-1 mediates the proapoptotic but not cell cycle arrest effects of the steroidal antiestrogen ICI 182,780 (faslodex, fulvestrant). Cancer Res. 2004, 64, 4030-4039.

53 Cook, K.L.; Shajahan, A.N.; Warri, A.; Jin, L.; Hilakivi-Clarke, L.A.; Clarke, R. Glucose-regulated protein 78 controls cross-talk between apoptosis and autophagy to determine antiestrogen responsiveness. Cancer Res. 2012, 72, 3337-3349.

54 Crawford, A.C.; Riggins, R.B.; Shajahan, A.N.; Zwart, A.; Clarke, R. Co-inhibition of BCL-W and BCL2 restores antiestrogen sensitivity through BECN1 and promotes an autophagy-associated necrosis. PLoS One 2010, 5, e8604.

55 Gomez, B.P.; Riggins, R.B.; Shajahan, A.N.; Klimach, U.; Wang, A.; Crawford, A.C.; Zhu, Y.; Zwart, A.; Wang, M.; Clarke, R. Human X-box binding protein-1 confers both estrogen independence and antiestrogen resistance in breast cancer cell lines. FASEB J. 2007, 21, 4013-4027.

56 Nehra, R.; Riggins, R.B.; Shajahan, A.N.; Zwart, A.; Crawford, A.C.; Clarke, R. BCL2 and CASP8 regulation by NF-kappaB differentially affect mitochondrial function and cell fate in antiestrogen-sensitive and -resistant breast cancer cells. FASEB J. 2010, 24, 2040-2055.

57 Riggins, R.B.; Zwart, A.; Nehra, R.; Clarke, R. The nuclear factor kappa B inhibitor parthenolide restores ICI 182,780 (Faslodex; fulvestrant)-induced apoptosis in antiestrogen-resistant breast cancer cells. Mol. Cancer Ther. 2005, 4, 33-41.

58 Shajahan, A.N.; Wang, A.; Decker, M.; Minshall, R.D.; Liu, M.C.; Clarke, R. Caveolin-1 tyrosine phosphorylation enhances paclitaxel-mediated cytotoxicity. J. Biol. Chem. 2007, 282, 5934-5943.

59 Shajahan, A.N.; Dobbin, Z.C.; Hickman, F.E.; Dakshanamurthy, S.; Clarke, R. Tyrosine-phosphorylated caveolin-1 (Tyr-14) increases sensitivity to paclitaxel by inhibiting BCL2 and BCLxL proteins via c-Jun N-terminal kinase (JNK). J. Biol. Chem. 2012, 287, 17682-17692.

60 Miller, T.W.; Balko, J.M.; Ghazoui, Z.; Dunbier, A.; Anderson, H.; Dowsett, M.; Gonzalez-Angulo, A.M.; Mills, G.B.; Miller, W.R.; Wu, H.; et al. A gene expression signature from human breast cancer cells with acquired hormone independence identifies MYC as a mediator of antiestrogen resistance. Clin. Cancer Res. 2011, 17, 2024-2034.

61 Musgrove, E.A.; Sergio, C.M.; Loi, S.; Inman, C.K.; Anderson, L.R.; Alles, M.C.; Pinese, M.; Caldon, C.E.; Schutte, J.; Gardiner-Garden, M.; et al. Identification of functional networks of estrogenand c-Myc-responsive genes and their relationship to response to tamoxifen therapy in breast cancer. PLoS One 2008, 3, e2987.

62 Wang, J.; Yin, Y.; Hua, H.; Li, M.; Luo, T.; Xu, L.; Wang, R.; Liu, D.; Zhang, Y.; Jiang, Y. Blockade of GRP78 sensitizes breast cancer cells to microtubules-interfering agents that induce the unfolded protein response. J. Cell Mol. Med. 2009, 13, 3888-3897.

63 Hart, L.S.; Cunningham, J.T.; Datta, T.; Dey, S.; Tameire, F.; Lehman, S.L.; Qiu, B.; Zhang, H.; Cerniglia, G.; Bi, M.; et al. ER stress-mediated autophagy promotes Myc-dependent transformation and tumor growth. J. Clin. Invest. 2012, 122, 4621-4634.

64 Shajahan-Haq, A.N.; Cook, K.L.; Schwartz-Roberts, J.L.; Eltayeb, A.E.; Demas, D.M.; Warri, A.M.; Facey, C.O.; Hilakivi-Clarke, L.A.; Clarke, R. MYC regulates the unfolded protein response and glucose and glutamine uptake in endocrine resistant breast cancer. Mol. Cancer 2014, 13, 239.

65 Deyati, A.; Younesi, E.; Hofmann-Apitius, M.; Novac, N. Challenges and opportunities for oncology biomarker discovery. Drug Discov. Today 2013, 18, 614-624. 
66 Armitage, E.G.; Barbas, C. Metabolomics in cancer biomarker discovery: Current trends and future perspectives. J. Pharm. Biomed. Anal. 2014, 87, 1-11.

67 Yin, P.; Xu, G. Metabolomics for tumor marker discovery and identification based on chromatography-mass spectrometry. Expert Rev. Mol. Diagn. 2013, 13, 339-348.

68 Gupta, S.; Chawla, K. Oncometabolomics in cancer research. Expert Rev. Proteomics 2013, 10, 325-336.

69 Wood, S.L.; Westbrook, J.A.; Brown, J.E. Omic-profiling in breast cancer metastasis to bone: implications for mechanisms, biomarkers and treatment. Cancer Treat. Rev. 2014, 40, 139-152.

70 Duarte, I.F.; Gil, A.M. Metabolic signatures of cancer unveiled by NMR spectroscopy of human biofluids. Prog. Nucl. Magn. Reson. Spectrosc. 2012, 62, 51-74.

71 Kumar, V.; Dwivedi, D.K.; Jagannathan, N.R. High-resolution NMR spectroscopy of human body fluids and tissues in relation to prostate cancer. NMR Biomed. 2014, 27, 80-89.

72 Williams, M.D.; Reeves, R.; Resar, L.S.; Hill, H.H., Jr. Metabolomics of colorectal cancer: past and current analytical platforms. Anal. Bioanal. Chem. 2013, 405, 5013-5030.

73 Blekherman, G.; Laubenbacher, R.; Cortes, D.F.; Mendes, P.; Torti, F.M.; Akman, S.; Torti, S.V.; Shulaev, V. Bioinformatics tools for cancer metabolomics. Metabolomics 2011, 7, 329-343.

74 Johnson, C.H.; Gonzalez, F.J. Challenges and opportunities of metabolomics. J. Cell Physiol. 2012, 227, 2975-2981.

75 Zhou, B.; Xiao, J.F.; Tuli, L.; Ressom, H.W. LC-MS-based metabolomics. Mol. Biosyst. 2012, 8, 470-481.

76 Mamas, M.; Dunn, W.B.; Neyses, L.; Goodacre, R. The role of metabolites and metabolomics in clinically applicable biomarkers of disease. Arch. Toxicol. 2011, 85, 5-17.

77 Vermeersch, K.A.; Styczynski, M.P. Applications of metabolomics in cancer research. J. Carcinog. 2013, 12, 9 .

78 Hsu, P.P.; Sabatini, D.M. Cancer cell metabolism: Warburg and beyond. Cell 2008, 134, 703-707.

79 Locasale, J.W.; Vander Heiden, M.G.; Cantley, L.C. Rewiring of glycolysis in cancer cell metabolism. Cell Cycle 2010, 9, 4253.

80 Munoz-Pinedo, C.; El, M.N.; Ricci, J.E. Cancer metabolism: Current perspectives and future directions. Cell Death Dis. 2012, 3, e248.

81 Vander Heiden, M.G.; Locasale, J.W.; Swanson, K.D.; Sharfi, H.; Heffron, G.J.; Amador-Noguez, D.; Christofk, H.R.; Wagner, G.; Rabinowitz, J.D.; Asara, J.M.; et al. Evidence for an alternative glycolytic pathway in rapidly proliferating cells. Science 2010, 329, 1492-1499.

82 Vander Heiden, M.G. Exploiting tumor metabolism: Challenges for clinical translation. J. Clin. Invest. 2013, 123, 3648-3651.

83 Asiago, V.M.; Alvarado, L.Z.; Shanaiah, N.; Gowda, G.A.; Owusu-Sarfo, K.; Ballas, R.A.; Raftery, D. Early detection of recurrent breast cancer using metabolite profiling. Cancer Res. 2010, 70, 8309-8318.

84 Cadoo, K.A.; Fornier, M.N.; Morris, P.G. Biological subtypes of breast cancer: current concepts and implications for recurrence patterns. Q. J. Nucl. Med. Mol. Imaging. 2013, 57, 312-321.

85 Curtis, C.; Shah, S.P.; Chin, S.F.; Turashvili, G.; Rueda, O.M.; Dunning, M.J.; Speed, D.; Lynch, A.G.; Samarajiwa, S.; Yuan, Y. The genomic and transcriptomic architecture of 2000 breast tumours reveals novel subgroups. Nature 2012, 486, 346-352. 
86 Finley, L.W.; Carracedo, A.; Lee, J.; Souza, A.; Egia, A.; Zhang, J.; Teruya-Feldstein, J.; Moreira, P.I.; Cardoso, S.M.; Clish, C.B.; et al. SIRT3 opposes reprogramming of cancer cell metabolism through HIF1alpha destabilization. Cancer Cell 2011, 19, 416-428.

87 Weljie, A.M.; Bondareva, A.; Zang, P.; Jirik, F.R. ${ }^{1} \mathrm{H}$ NMR metabolomics identification of markers of hypoxia-induced metabolic shifts in a breast cancer model system. J. Biomol. NMR 2011, 49, 185-193.

88 Budczies, J.; Brockmoller, S.F.; Muller, B.M.; Barupal, D.K.; Richter-Ehrenstein, C.; Kleine-Tebbe, A.; Griffin, J.L.; Oresic, M.; Dietel, M.; Denkert, C.; et al. Comparative metabolomics of estrogen receptor positive and estrogen receptor negative breast cancer: Alterations in glutamine and beta-alanine metabolism. J. Proteomics 2013, 94, 279-288.

89 Jobard, E.; Pontoizeau, C.; Blaise, B.J.; Bachelot, T.; Elena-Herrmann, B.; Tredan, O. A serum nuclear magnetic resonance-based metabolomic signature of advanced metastatic human breast cancer. Cancer Lett. 2014, 343, 33-41.

90 Qiu, Y.; Zhou, B.; Su, M.; Baxter, S.; Zheng, X.; Zhao, X.; Yen, Y.; Jia, W. Mass spectrometrybased quantitative metabolomics revealed a distinct lipid profile in breast cancer patients. Int. J. Mol. Sci. 2013, 14, 8047-8061.

91 Bayet-Robert, M.; Morvan, D. Metabolomics reveals metabolic targets and biphasic responses in breast cancer cells treated by curcumin alone and in association with docetaxel. PLoS One 2013, 8, e57971.

92 Brauer, H.A.; Makowski, L.; Hoadley, K.A.; Casbas-Hernandez, P.; Lang, L.J.; Roman-Perez, E.; D’Arcy, M.; Freemerman, A.J.; Perou, C.M.; Troester, M.A. Impact of tumor microenvironment and epithelial phenotypes on metabolism in breast cancer. Clin. Cancer Res. 2013, 19, 571-585.

93 Mandujano-Tinoco, E.A.; Gallardo-Perez, J.C.; Marin-Hernandez, A.; Moreno-Sanchez, R.; Rodriguez-Enriquez, S. Anti-mitochondrial therapy in human breast cancer multi-cellular spheroids. Biochim. Biophys. Acta 2013, 1833, 541-551.

94 Wei, S.; Liu, L.; Zhang, J.; Bowers, J.; Gowda, G.A.; Seeger, H.; Fehm, T.; Neubauer, H.J.; Vogel, U.; Clare, S.E.; et al. Metabolomics approach for predicting response to neoadjuvant chemotherapy for breast cancer. Mol. Oncol. 2013, 7, 297-307.

95 Budczies, J. Remodeling of central metabolism in invasive breast cancer compared to normal breast tissue - a GC-TOFMS based metabolomics study. BMC Genomics 2012, doi:10.1186/14712164-13-334.

96 Martinez-Outschoorn, U.E.; Prisco, M.; Ertel, A.; Tsirigos, A.; Lin, Z.; Pavlides, S.; Wang, C.; Flomenberg, N.; Knudsen, E.S.; Howell, A.; et al. Ketones and lactate increase cancer cell "stemness," driving recurrence, metastasis and poor clinical outcome in breast cancer: achieving personalized medicine via Metabolo-Genomics. Cell Cycle 2011, 10, 1271-1286.

97 Yang, M.; Soga, T.; Pollard, P.J.; Adam, J. The emerging role of fumarate as an oncometabolite. Front. Oncol. 2012, 2, 85.

98 Turcan, S.; Rohle, D.; Goenka, A.; Walsh, L.A.; Fang, F.; Yilmaz, E.; Campos, C.; Fabius, A.W.; Lu, C.; Ward, P.S.; et al. IDH1 mutation is sufficient to establish the glioma hypermethylator phenotype. Nature 2012, 483, 479-483. 
99 Jain, M.; Nilsson, R.; Sharma, S.; Madhusudhan, N.; Kitami, T.; Souza, A.L.; Kafri, R.; Kirschner, M.W.; Clish, C.B.; Mootha, V.K. Metabolite profiling identifies a key role for glycine in rapid cancer cell proliferation. Science 2012, 336, 1040-1044.

100 Claudino, W.M.; Goncalves, P.H.; Di, L.A.; Philip, P.A.; Sarkar, F.H. Metabolomics in cancer: A bench-to-bedside intersection. Crit. Rev. Oncol. Hematol. 2012, 84, 1-7.

101 Nordstrom, A.; Lewensohn, R. Metabolomics: Moving to the clinic. J. Neuroimmune Pharmacol. 2010, 5, 4-17.

102 O'Connell, T.M. Recent advances in metabolomics in oncology. Bioanalysis 2012, 4, 431-451.

103 Benjamin, D.I.; Cravatt, B.F.; Nomura, D.K. Global profiling strategies for mapping dysregulated metabolic pathways in cancer. Cell Metab. 2012, 16, 565-577.

104 Chou, H.C.; Chan, H.L. Targeting proteomics to investigate metastasis-associated mitochondrial proteins. J. Bioenerg. Biomembr. 2012, 44, 629-634.

105 Ma, Y.; Zhang, P.; Yang, Y.; Wang, F.; Qin, H. Metabolomics in the fields of oncology: A review of recent research. Mol. Biol. Rep. 2012, 39, 7505-7511.

106 Cao, B.; Li, M.; Zha, W.; Zhao, Q.; Gu, R.; Liu, L.; Shi, J.; Zhou, J.; Zhou.; F.; Wu, X.; et al. Metabolomic approach to evaluating adriamycin pharmacodynamics and resistance in breast cancer cells. Metabolomics 2013, 9, 960-973.

107 Tsai, I.L.; Kuo, T.C.; Ho, T.J.; Harn, Y.C.; Wang, S.Y.; Fu, W.M.; Kuo, C.H.; Tseng, Y.J. Metabolomic Dynamic Analysis of Hypoxia in MDA-MB-231 and the Comparison with Inferred Metabolites from Transcriptomics Data. Cancers 2013, 5, 491-510.

108 Morvan, D. Functional metabolomics uncovers metabolic alterations associated to severe oxidative stress in MCF7 breast cancer cells exposed to ascididemin. Mar. Drugs 2013, 11, 3846-3860.

109 Bayet-Robert, M.; Morvan, D. Metabolomics reveals metabolic targets and biphasic responses in breast cancer cells treated by curcumin alone and in association with docetaxel. PLoS One 2013, 8, e57971.

110 Jager, W.; Gruber, A.; Giessrigl, B.; Krupitza, G.; Szekeres, T.; Sonntag, D. Metabolomic analysis of resveratrol-induced effects in the human breast cancer cell lines MCF-7 and MDA-MB-231. OMICS 2011, 15, 9-14.

111 Slupsky, C.M.; Steed, H.; Wells, T.H.; Dabbs, K.; Schepansky, A.; Capstick, V.; Faught, W.; Sawyer, M.B. Urine metabolite analysis offers potential early diagnosis of ovarian and breast cancers. Clin. Cancer Res. 2010, 16, 5835-5841.

112 Nicholson, J.K.; Wilson, I.D.; Lindon, J.C. Pharmacometabonomics as an effector for personalized medicine. Pharmacogenomics 2011, 12, 103-111.

113 Ram, P.T.; Mendelsohn, J.; Mills, G.B. Bioinformatics and systems biology. Mol. Oncol. 2012, 6, $147-154$.

114 Denkert, C.; Bucher, E.; Hilvo, M.; Salek, R.; Oresic, M.; Griffin, J.; Brockmoller, S.; Klauschen, F.; Loibl, S.; Barupal, D.K.; et al. Metabolomics of human breast cancer: New approaches for tumor typing and biomarker discovery. Genome Med. 2012, 4, 37.

115 Peintinger, F. Using molecular profiles to tailor treatment in breast cancer: Are they ready for prime time? Curr. Opin. Obstet. Gynecol. 2014, 26, 21-26.

116 Hood, L.; Flores, M. A personal view on systems medicine and the emergence of proactive P4 medicine: Predictive, preventive, personalized and participatory. N. Biotechnol. 2012, 29, 613-624. 
117 Hood, L.; Auffray, C. Participatory medicine: A driving force for revolutionizing healthcare. Genome Med. 2013, 5, 110.

118 Hood, L. Systems biology and p4 medicine: Past, present, and future. Rambam Maimonides Med. J. 2013, 4, e0012.

119 Cesario. A.; Auffray, C.; Russo, P.; Hood, L. P4 Medicine Needs P4 Education. Curr. Pharm. Des. 2014, 20, 6071-6072.

120 Bu, Q.; Huang, Y.; Yan, G.; Cen, X.; Zhao, Y.L. Metabolomics: A revolution for novel cancer marker identification. Comb. Chem. High Throughput Screen. 2012, 15, 266-275.

121 Wang, J.H.; Byun, J.; Pennathur, S. Analytical approaches to metabolomics and applications to systems biology. Semin. Nephrol. 2010, 30, 500-511.

122 Casado-Vela, J.; Cebrian, A.; Gomez del Pulgar, M.T.; Lacal, J.C. Approaches for the study of cancer: Towards the integration of genomics, proteomics and metabolomics. Clin. Transl. Oncol. 2011, 13, 617-628.

123 Fan, T.W.; Lorkiewicz, P.K.; Sellers, K.; Moseley, H.N.; Higashi, R.M.; Lane, A.N. Stable isotope-resolved metabolomics and applications for drug development. Pharmacol. Ther. 2012, 133, 366-391.

124 Xiao, J.F.; Zhou, B.; Ressom, H.W. Metabolite identification and quantitation in LC-MS/MS-based metabolomics. Trends Analyt. Chem. 2012, 32, 1-14.

125 Ganapathy-Kanniappan, S.; Geschwind, J.F. Tumor glycolysis as a target for cancer therapy: progress and prospects. Mol. Cancer 2013, 12, 152.

126 DeBerardinis, R.J.; Cheng, T. Q's next: The diverse functions of glutamine in metabolism, cell biology and cancer. Oncogene 2010, 29, 313-324.

127 Lu, C.W.; Lin, S.C.; Chen, K.F.; Lai, Y.Y.; Tsai, S.J. Induction of pyruvate dehydrogenase kinase3 by hypoxia-inducible factor-1 promotes metabolic switch and drug resistance. J. Biol. Chem. 2008, 283, 28106-28114.

128 Fanciulli, M.; Bruno, T.; Giovannelli, A.; Gentile, F.P.; Di, P.M.; Rubiu, O.; Floridi, A. Energy metabolism of human LoVo colon carcinoma cells: Correlation to drug resistance and influence of lonidamine. Clin. Cancer Res. 2000, 6, 1590-1597.

129 Bonnet, S.; Archer, S.L.; Allalunis-Turner, J.; Haromy, A.; Beaulieu, C.; Thompson, R.; Lee, C.T.; Lopaschuk, G.D.; Puttagunta, L.; Bonnet, S.; et al. A mitochondria-K+ channel axis is suppressed in cancer and its normalization promotes apoptosis and inhibits cancer growth. Cancer Cell 2007, $11,37-51$.

130 Horecker, B.L. The pentose phosphate pathway. J. Biol. Chem. 2002, 277, 47965-47971.

131 Estrela, J.M.; Ortega, A.; Obrador, E. Glutathione in cancer biology and therapy. Crit. Rev. Clin. Lab. Sci. 2006, 43, 143-181.

132 Backos, D.S.; Franklin, C.C.; Reigan, P. The role of glutathione in brain tumor drug resistance. Biochem. Pharmacol. 2012, 83, 1005-1012.

$133 \mathrm{Xu}, \mathrm{X}$; Zur, H.A.; Coy, J.F.; Lochelt, M. Transketolase-like protein 1 (TKTL1) is required for rapid cell growth and full viability of human tumor cells. Int. J. Cancer 2009, 124, 1330-1337. 
134 Monteleone, F.; Rosa, R.; Vitale, M.; D’Ambrosio, C.; Succoio, M.; Formisano, L.; Nappi, L.; Romano, M.F.; Scaloni, A.; Tortora, G.; et al. Increased anaerobic metabolism is a distinctive signature in a colorectal cancer cellular model of resistance to antiepidermal growth factor receptor antibody. Proteomics 2013, 13, 866-877.

135 Zhao, F.; Mancuso, A.; Bui, T.V.; Tong, X.; Gruber, J.J.; Swider, C.R.; Sanchez, P.V.; Lum, J.J.; Sayed, N.; Melo, J.V.; et al. Imatinib resistance associated with BCR-ABL upregulation is dependent on HIF-1alpha-induced metabolic reprograming. Oncogene 2010, 29, 2962-2972.

136 Chen, J.; Zhang, S.; Li, Y.; Tang, Z.; Kong, W. Hexokinase 2 overexpression promotes the proliferation and survival of laryngeal squamous cell carcinoma. Tumor Biol. 2013, 35, 3743-3753.

137 Gershon, T.R.; Crowther, A.J.; Tikunov, A.; Garcia, I.; Annis, R.; Yuan, H.; Miller, C.R.; Macdonald, J.; Olson, J.; Deshmukh, M. Hexokinase-2-mediated aerobic glycolysis is integral to cerebellar neurogenesis and pathogenesis of medulloblastoma. Cancer Metab. 2013, doi:10.1186/2049-3002-1-2.

138 Puzone, R.; Savarino, G.; Salvi, S.; Dal Bello, M.G.; Barletta, G.; Genova, C.; Rijavec, E.; Sini, C.; Esposito, A.I.; Ratto, G.B.; et al. Glyceraldehyde-3-phosphate dehydrogenase gene over expression correlates with poor prognosis in non small cell lung cancer patients. Mol. Cancer 2013, 12, 97.

139 Jacquin, M.A.; Chiche, J.; Zunino, B.; Beneteau, M.; Meynet, O.; Pradelli, L.A.; Marchetti, S.; Cornille, A.; Carles, M.; Ricci, J.E. GAPDH binds to active Akt, leading to Bcl-xL increase and escape from caspase-independent cell death. Cell Death Differ. 2013, 20, 1043-1054.

140 Christofk, H.R.; Vander Heiden, M.G.; Harris, M.H.; Ramanathan, A.; Gerszten, R.E.; Wei, R.; Fleming, M.D.; Schreiber, S.L.; Cantley, L.C. The M2 splice isoform of pyruvate kinase is important for cancer metabolism and tumour growth. Nature 2008, 452, 230-233.

141 Luo, W.; Semenza, G.L. Pyruvate kinase M2 regulates glucose metabolism by functioning as a coactivator for hypoxia-inducible factor 1 in cancer cells. Oncotarget 2011, 2, 551-556.

142 Hussien, R.; Brooks, G.A. Mitochondrial and plasma membrane lactate transporter and lactate dehydrogenase isoform expression in breast cancer cell lines. Physiol. Genomics 2011, 43, 255-264.

143 Csibi, A.; Blenis, J. Appetite for destruction: the inhibition of glycolysis as a therapy for tuberous sclerosis complex-related tumors. BMC Biol. 2011, 9, 69.

144 Kim, S.K.; Jung, W.H.; Koo, J.S. Differential expression of enzymes associated with serine/glycine metabolism in different breast cancer subtypes. PLoS One 2014, 9, e101004.

(C) 2015 by the authors; licensee MDPI, Basel, Switzerland. This article is an open access article distributed under the terms and conditions of the Creative Commons Attribution license (http://creativecommons.org/licenses/by/4.0/). 